\title{
O Antigo versus o Moderno: o Debate Histórico De GotTsched, BodMER E BREITINGER
} Old versus Modern: The Historical Debate between
Gottsched, Bodmer and Breitinger

\author{
Michael Korfmann*
}

\section{INTRODUÇÃo}

Historicamente, a autonomia da literatura e arte - como um dos campos sociais funcionais da sociedade moderna - ganha forma no final do século XVIII, documentada nas discussões entre os moderni e antiqui. Não é raro encontrar no final do século XVIII posições como a de Johann Gottfried Herder, que, em um panfleto literário ainda marcado pela disputa da época entre o velho e o novo, avaliou, em 1778, a poesia da Europa antiga. Para Herder, defensor destacado de uma literatura que, na virada do século, se autodefinia como moderna, não havia dúvida: a literatura do tempo passado era uma matéria didática e sem vida, escrita por pedantes senis e mestres dispostos a passar as regras poéticas a todo custo. O que contava para eles era imitar os grandes escritores gregos e romanos, mas, conforme Herder (1778), não possuíam talento nem efeito verdadeiro sobre o público ou um sentimento vivo próprio.

Eruditos escreviam para eruditos, pedantes para pedantes, a maioria [...] incapazes de transmitir a força poética. Para esses, a ação de escrever não exigia talento poético, força ou a intenção de 
impressionar o leitor. Os padrões dos velhos estavam lá e somente era preciso escrever como eles, em frases bonitas e reguladas, conforme as pobres regras formais e externas [...] E assim a poesia se tornou aquela coisa morna, que ninguém consegue apreciar (HERDER, 1982, p. 221).

Também os irmãos Schlegel viam na literatura do século XVIII e início do século XIX pouco mais que regras colocadas em prática e, ainda em 1810, Eichendorff falava de uma literatura feita de "enciclopédias que se tornaram malucas". Mesmo a teoria moderna literária contemporânea não está tão longe das avaliações feitas pelos românticos e vê a literatura do barroco e do iluminismo como resultado de uma rígida poética reguladora. Para essa continuidade contribui certamente a estrutura retórica de suas regras. O que se sabia e aprendia até aproximadamente 1750 sobre literatura, dentro da tradição da Europa antiga, devia-se a uma poética cujas regras e indicações seguiam detalhadamente as leis da retórica e sua sistemática escolástica. A poética da Europa antiga é uma ars que recebe todos os campos de sua atuação como questões de disposição formal, de realização linguística ou de recepção do sistema retórico e, assim, não se apresenta como arte no sentido moderno - uma criação original -, mas como uma união entre a praxe e seu conhecimento teórico. Nesta configuração, destaca-se o conceito de adequado para um assunto e seu trato no discurso, o chamado aptum ou decorum, como mecanismo de controle. Como regra absoluta, primeiro da retórica e depois da poética, esse princípio decidiu, na antiga sociedade europeia, estruturada de maneira estratificada, sobre a verdade e o bom da expressão verbal. 0 aptum exige um uso apropriado das palavras para o assunto representado, bem como um estilo adequado ao público endereçado. Disso derivou a teoria dos três estilos, o estilo elevado da poesia, o médio da ciência e o baixo. Era proibido utilizar um estilo elevado para a classe baixa. Diferencia-se o aptum interno, que coordenava as fases da produção do texto, do aptum externo, que ligava-o às suas condições externas como lugar, tempo, ocasião, público etc. Além de ser uma instrução técnica, já que um resultado eficiente do ato elocutivo somente poderia ser alcançado obedecendo-se ao aptum, exerceu uma função estabilizadora para o sistema político estratificador.

A base do aptum ou decorum é constituída por uma semântica conforme a qual os objetos encontram-se numa ordem hierárquica análoga à dos homens. Além disso, a graduação das coisas, que se orienta nos três níveis de baixo, médio e elevado, precisa repetir-se na mimesis através da graduação do nível linguístico. O estilo, além de ser correspondente à hierarquia das coisas, precisa ser escolhido adequadamente conforme a classe, tempo, lugar e ocasião. Assim, o aptum exige do poeta um posicionamento 
ético e político: "somente quem sabe e respeita o que se deve fazer na ordem social é capaz de exercer o aptum no discurso e praticar uma fala certa até na escolha de cada palavra" (FISCHER, 1968, p. 193).

Respeitando o aptum, o poeta não se torna apenas um discursador perfeito, mas, paralelamente, um vir bonus, que contribui com atividades de valor moral, no seu caso a sua poética, para o "melhoramento da convivência humana" (FISCHER, 1968, p. 241). O aptum não se restringe a ser uma teoria poética básica que sustenta toda estrutura de regras da teoria literária da época, mas exerce também uma função de vigilância política. Ele dirige a comunicação estética a partir do ponto de vista ético e político de uma sociedade baseada num princípio estratificador. A poética de gêneros mostra a mesma característica. A distribuição dos gêneros não é feita conforme razões estéticas, mas conforme o princípio da estratificação. A epopeia e a tragédia, com personagens como reis e comandantes militares, representam os gêneros mais altos. Eles exigem o stilus grande, sintaticamente bem estilizado e ornamentado, enquanto à comédia e aos pastorais cabe a forma genus humile (SCHERPE, 1968, p. 16), com uma diç̧ão próxima do uso cotidiano.

August Buchner, na sua publicação Weg-Weiser (Itinerário) de 1663 prescreve:

[...] Também as poesias devem ser diferenciadas conforme seus temas [...] O primeiro tipo é a poesia heróica, na qual são contados e louvados as vidas e fazeres de grandes senhores. Segue-se a tragédia, que apresenta conflitos terríveis e cruéis de pessoas de classe alta, enquanto a comédia apenas trata de assuntos que o homem comum enfrenta no seu dia-a-dia (BUCHNER,1977, p. 63).

No iluminismo se desarticulou a ordem rígida, estruturada hierarquicamente. As discussões sobre o velho e o novo, emergidas das dúvidas sobre as estruturas tradicionais, a autoridade e a razão, a norma e o juízo livre, ainda não eram capazes de substituir a semântica da ordem feudal, mas situaram o pensamento crítico no campo da moral. "O anseio por uma ordem nova levava a um florescimento dos discursos morais" (LUHMANN, 1993, p. 379).

A cultura da corte, com sua ênfase na representação, atende à aparência. O comportamento oficial, conforme as regras do costume, a teatralidade e a hipocrisia da cultura da corte, são condenados pelos iluministas como artificiais. Contra essa artificialidade da corte e diante do aumento de poder da burguesia, a comunicação estética começa a se estender a um público mais amplo. A mimesis artística se concentra agora no esclarecimento moral. Seu objeto é a natureza, que se pode descrever como 
racional e moralista. Gottsched (1730) entende que a probabilidade poética não é nada mais que a similaridade da criação poética, os mundos a serem realizados poeticamente com essa natureza, e enfatiza a "concordância da fábula com a natureza" (GOTTSCHED, 1982, p. 129). Assim, a literatura dos mundos inventados deve possuir as mesmas referências, coerência interna e consistência do mundo real, sendo potencialmente racional e moralista. Nas duas dimensões reinam, conforme Breitinger (1740) as mesmas leis eternas, nas quais se encontra a beleza do cosmos. "Todos esses mundos possíveis, mesmo sendo não reais e não visíveis, possuem uma verdade própria, que é fundada na sua potencialidade, livre de toda arbitrariedade, e no poder total do criador da natureza" (BREITINGER, 1980, p. 86).

Esse paradigma da poética da Europa antiga nos escritos de Johann Christoph Gottsched, Johann Jakob Bodmer e Johann Jakob Breitinger é analisado em seguida mais detalhadamente. Apesar de sua inserção no pensamento antigo, encontram-se em seus textos certos traços e reflexões iniciais sobre a diferenciação da literatura em direção a um campo próprio que objetiva se distanciar das delimitações sociais e estéticas externas.

\section{O Debate}

As condições de produção e recepção da arte na Europa antiga não são reguladas por uma estética específica como parte da autorreflexão artística, mas constituídas por grêmios externos que supervisionam e avaliam permanentemente o valor da obra literária. No caso de Gottsched, similar ao de outros iluministas, é a moral que exerce a função de presidir o julgamento poético.

Conforme o autor (1730), o iluminismo precisa da poesia para melhorar, através de exemplos de caráter moral, as mentes, facilmente influenciadas pelos sentidos, pois essas mentes dificilmente poderiam ser alcançadas por um argumento que "consiste apenas de conclusões racionais" (GOTTSCHED, 1982, p. 6). Por isso, ele defende uma estratégia efetiva que "veste uma tese de ensino moral para que, poeticamente, ensine e deleite igualmente pessoas com ou sem instrução" (GOTTSCHED, 1982, p. 102). O resultado precisa, então, passar ainda pelos "exames da razão" Gottsched recorre à imitação da natureza e, com isso, à garantia transcendental, para garantir a beleza:

Deus criou tudo conforme números, medidas e peso. As coisas naturais são belas; se a arte também pretende criar algo belo, ela precisa imitar a estrutura da natureza. A imitação da natureza 
pode, então, atribuir perfeição à obra artística, que se torna assim agradável e amável para a razão (GOTTSCHED, 1982, p. 70).

A hegemonia moral sobre a literatura, sob o controle racional do iluminismo, se estende para um período maior. $O$ autor Charles Batteux, muito traduzido e lido na Alemanha dessa época, enfatiza na sua obra Les Beaux-Arts réduits à un même principe, de 1746, explicitamente a identidade semântica do bom e do belo: "Os objetos das artes são o bom e o belo, duas palavras que quase tem o mesmo significado olhando de perto" (1976, p. 211). A combinação de uma dogmática de imitação com um ímpeto esclarecedor cria uma semântica na qual o belo, o verdadeiro e o bem se misturam. Gottsched (1730) pressupõe que um poeta imita as ações do homem, que são ou boas ou ruins. Ele precisaria, então, reproduzir as boas como o bom, quer dizer, de forma bela, louvável e atraente, e as ruins como o ruim, ou seja, de forma feia, vergonhosa e repugnante. O contrário não seria aceitável, pois o poeta não estaria fazendo jus à lei da mimesis: "se ele não fizer isso e se arriscar em apresentar a virtude como desprezível, danosa e ridícula e o vício como agradável, vantajoso e louvável, ele perderá a semelhança da vista e expressará a natureza da mesma muito mal" (GOTTSCHED, 1982, p. 51).

Também nos escritos de Klopstock, de cunho mais religioso, o mal e o belo são contradictio in adiecto. A poesia mais elevada é totalmente incapaz de nos seduzir, através de imagens deslumbrantes, na direção do mal. No momento em que ela tentasse fazer isto, "deixaria de ser o que ela é" (KLOPSTOCK, 1989, p. 191). Breitinger parece ir mais longe que Gottsched e Klopstock. Nos conceitos de ambos, o feio sempre carrega consigo a marca do mal e desagrada por princípio, porque repugna o leitor e não o estimula a uma imitação. Breitinger (1740), ao contrário, descobre o gosto do feio, como mostra a crítica feita a um poema de Brockes que, ao retratar uma mulher, usa os versos:

Cheio de ranho viscoso e escarro, os lábios inchados e azuis o peito frouxo e caído, as costelas magras e secas O pescoço torto e tremendo, as costas corcundas o queixo de osso, as cavernas da face murcha (BREITINGER, 1980, p. 94).

Breitinger argumenta a seu favor, recorrendo a conceitos de Aristóteles. Não é o corpo repugnante da mulher que agrada, mas a qualidade da imitação. O feio se torna aceitável esteticamente quando ele evoca um "deleite, que a imitação habilidosa da arte consegue através do seu poder 
particular" (BREITINGER, 1980, p. 96). Breitinger valoriza, então, dentro da diferença entre forma e conteúdo, o primeiro aspecto. Ele diz conhecer obras-primas que obtém "seus méritos não da matéria das suas apresentações, mas da arte, que seus criadores comprovaram na imitação. Nelas, admira-se o pincel, que conseguiu imitar a natureza tão perfeitamente" (1980, p. 104).

Dentro dessa linha de argumentação, Bodmer e Breitinger podem declarar como belas certas obras que, conforme a teoria ontológica de Gottsched, deveriam ser consideradas feias:

A descrição do vício, da maldade, da feiúra, do terrível, do triste também causa deleite quando são feitas de uma maneira natural. [...] resumindo, tudo que é imitado com perfeição se torna agradável. Aristóteles tinha razão quando comentou que aquele deleite causado pela observação de uma bela imitação não vinha do objeto dado, mas da reflexão (BODMER; BREITINGER, 1980, p. 12).

Apoiando-se na autoridade máxima de Aristóteles, Breitinger declara que, na pintura, nas artes plásticas e na poesia, obtém-se "deleite" mesmo sendo os objetos imitados de caráter desagradável, desde que o resultado seja "hábil, feliz e bem feito" (BODMER; BREITINGER, 1980, p. 96).

Poder-se-ia aqui esperar a conclusão, que somente mais tarde é formulada pelos teóricos românticos, de que a qualidade poética da forma é decisiva para a beleza da obra e não a dignidade religiosa ou a aceitação social do conteúdo. Mas Breitinger desfaz novamente a postulada diferença entre forma e objeto. À arte não seria permitida a escolha livre de seus critérios para o ganho de formas. $O$ acesso a um arranjo esteticamente belo de matérias tradicionalmente consideradas desagradáveis é fechado de novo. As razões encontram-se no inculcar da semântica poética na ordem estratificatória do social.

A essa semântica poética corresponde, no nível da estrutura social, a diferenciação estratificadora "com sua unidade difusa de direito, moral, artes, gosto, poder e religião" (LUHMANN, 1980, p. 25). Em relação a Breitinger, essa estratificação obrigatória da poesia explica a renúncia, surpreendente à primeira vista, a uma estética de formas em favor da prevalência tradicional dos conteúdos: depois de ter enfatizado primeiramente que a arte não apenas agradaria no caso de um material belo, mas também através do processamento e bela formação desse material, mesmo quando a recepção da imagem original não fosse agradável na realidade, ele agora levanta a seguinte pergunta:

Como podemos ser tocados por uma cópia, quando o próprio original não o consegue? Como pode um quadro que mostra um agricultor 
com seus dois burros de carga chamar nossa atenção, quando a ação, imitada pela pintura, não nos atrai? Elogiamos o pintor por causa da sua arte, mas o criticamos por ter dedicado sua diligência a assuntos que nos dizem tão pouco respeito (BREITINGER, 1980, p. 104).

Apesar de toda a beleza do trabalho, o poeta não seria capaz de fazer de seu objeto uma peça boa se o conteúdo fosse escolhido erroneamente. Não é a arte que torna seus media belos, mas o contrário. A seleção central das temáticas é feita conforme os diversos gêneros. Para Breitinger, a escolha da matéria fica mais definida e limitada pelos diversos tipos e gêneros poéticos. Isso estratifica a poética, pois em relação ao conteúdo, o gênero poético era mais elevado, a tragédia, era exclusiva das classes mais altas, enquanto a comédia, localizada mais abaixo, tematizava os burgueses.

A tragédia procurava, através da apresentação de um destino duro e imprevisível que pessoas nobres sofressem por causa de seus atos errôneos, provocar tristeza, susto e compaixão nos espectadores e prepará- los para suas próprias desgraças. A comédia "mostra pessoas da classe burguesa para tornar ridículos, através da imitação, seus erros" (BODMER; BREITINGER, 1980, p. 107).

As tragédias, purificando os sentimentos através do susto e da compaixão, eram destinadas aos poderosos, para que fossem impedidos de cometer crueldades e "atos violentos". Enquanto esses purificar-se-iam pela catarse, as classes mais baixas precisariam contentar-se com lições para o cotidiano: "A comédia, um espelho da vida burguesa, mostra as falhas de pessoas comuns para que os chefes de família aprendam como liderar a sua família, corrigir seus erros e se satisfazer com sua classe social" (BODMER; BREITINGER, 1980, p. 119).

Conforme a classe, idade e dignidade da pessoa, as obras precisavam ser, na sua realização, "magníficas" ou "naturais e humildes". A hierarquia do gênero poético se inspirava diretamente na hierarquia da própria sociedade, e essa se baseava na natureza das coisas e, em última instância, em Deus. Reinhart Meyer destacou que, na concepção de Bodmer e Breitinger, a poeticidade de uma obra depende do ranking do tema tratado. Esse ranking resultaria do lugar ocupado por um ser na "corrente da existência, da sua proximidade ou sua distância de Deus” (MEYER, 1980, p. 68).

A poesia precisava ser, de acordo com a razão e a natureza humana, baseada no verdadeiro e no bom. O poeta seria um "mestre moral, que, dessa maneira, pode imitar o criador" (BODMER; BREITINGER, 1980, p. 224). Ele trabalharia como o artista mais elevado, o autor da natureza. Se a natureza divina fosse, por si, bela, ordenada, boa, justa e verdadeira, a arte que a imita também seria. Disso resulta uma ligação fixa entre qualidade poética e moral. "Por isso, não preciso considerar a poesia como arte imitadora, mas 
como presente do céu e uma ferramenta preciosa, que introduz verdade e virtude e expulsa o vício" (BODMER; BREITINGER, 1980, p. 120).

O círculo se fecha com a concepção de Breitinger, que exige da poesia também uma descrição do "vício" desprezível e feio, para fins de imitação, mas considera a ênfase magnífica da "virtude elevada" seu ponto mais alto. A reflexão de Breitinger sobre o "deleite" frente ao feio resulta numa diferenciação moralista entre um deleite danoso, prejudicial, e um deleite útil. $O$ deleite verdadeiro fornecido pela arte é reduzido e limitado à conservação dos "deveres naturais de cidadãos e cristãos" (BODMER; BREITINGER, 1980, p. 117), conforme sua respectiva classe social. Esses deveres também são naturalmente obrigatórios para o poeta. Tudo que fortalece essa posição e assim contribui para uma "felicidade verdadeira, tudo que é baseado, dessa maneira, no verdadeiro e no bom, alcançou como arte poética sua maior perfeição" (BODMER; BREITINGER, 1980, p. 117).

A beleza depende então primeiramente da classe e da virtude das pessoas, não das formas dos media. Reinhart Meyer afirma polemicamente que a concepção de Breitinger se baseia num "sistema de valores que define o significado de uma obra independentemente de suas qualidades artísticas" (MEYER, 1980, p. 68). Independente de tais avaliações, torna-se clara a interligação imutável do aspecto qualitativo, estético e do aspecto moral, ético nas concepções poéticas nesta fase histórica. Podemos ver as reflexões de Lessing, resumidas a seguir, como pensamento transitório em direção à já citada insistência na autonomia artística formulada pelos românticos. Diferentemente de Gottsched, que defende uma posição iluminista-racional, e Bodmer e Breitinger, encontrando-se entre o racional e o sensível, Lessing segue uma linha de argumentação que combina tanto o aspecto sensível, quanto o iluminista e o moralista. Ele enfatiza, no seu texto programático Dramaturgia de Hamburgo (1767-69), referindo-se a Aristóteles, Corneille e Voltaire, o efeito teatral da compaixão. Seu discurso não trata de uma verdade moral, nem de uma moral racional, mas do sentimento natural, o estímulo de afetos na prática, o que retira da poesia a função de intermediadora de (re)conhecimentos: "No teatro, não deveríamos aprender o que esta ou aquela pessoa fez, mas o que cada pessoa de um certo caráter faria sob certas condições" (LESSING, 1954, p. 101).

Conforme Klaus Dockhorn (1968, p. 89), isso ajuda o irracional a se descobrir e se articular, pois o delectare e o movere, como união do emocional, encontram-se num nível superior ao docere, colocando assim "o emocional e o irracional acima da razão". Entretanto, o teatro da compaixão exercia paralelamente a função, como instância da moral burguesa, de uma representação pública de caráter ético-político. Tomando posição contra as intrigas políticas da corte, esse teatro "passa da área privada para a arena pública, exigindo a subordinação da política aos valores dessa moral” (DURZAK, 1984, p. 135). 
A preocupação central de Lessing é o efeito moral sobre o público, a questão da eficiência em relação à evocação da compaixão. Nesse aspecto, parece-lhe sem sentido seguir regras poéticas, como, por exemplo, a das três unidades ou a da probabilidade baseada na realidade racional. Para Lessing, essa dramaturgia mecânica não faz jus à característica da arte. "Senhores redatores de regras gerais, como vocês entendem pouco de arte, como vocês possuem pouco do gênio que fez surgir os padrões nos quais vocês se baseiam e os quais podem ultrapassar sempre que quiser!" (LESSING, 1954, p. 248).

Alcançar-se-ia o maior efeito sobre o público através de uma ação emocionalmente cativante. Em relação à matéria da fábula, Lessing considera a história como um arsenal a ser explorado: "ao poeta, ela é a pedreira da qual ele constrói seu mundo” (KNODT, 1988, p. 130). Dessa história deve-se separar algo universal, que combina com a probabilidade interna da fábula. A mimesis não se dirige a uma imagem naturalista parcial, pois

na natureza tudo é interligado, tudo se cruza, tudo muda de um para outro [...]. O destino da arte é facilitar a fixação da nossa atenção. Tudo que nós, em nossos pensamentos, separamos de um objeto na natureza, ou desejamos separar, a arte separa de fato e nos concede esse objeto ou essa combinação de objetos diferentes (LESSING, 1954, p. 358).

O ponto central da produção artística, resultando na evocação de compaixão, não se encontraria na invenção da fábula, mas na apresentação das personagens. A probabilidade interna, que deveria transmitir credibilidade ao público para, então, obter uma compaixão mais intensa, se referia à probabilidade psicológica das personagens e a motivação exata da ação. "Ao poeta, as personagens precisam ser mais preciosas que os fatos. Quando se observa os primeiros com exatidão, os segundos, como consequência dos primeiros, não poderiam ter acontecido de forma diferente" (LESSING, 1954, p. 172). Para interessar ao público e convencê-lo, as personagens não deveriam ser nem melhores nem piores que costumamos ser, pois sendo excepcionais e incomuns, não seriam capazes de estimular o processo de simpatia indispensável à evocação da compaixão.

\section{Conclusões}

No pensamento Europeu pré-moderno, o conceito da imitação, para a arte, foi ligado a dois caminhos: tanto a mimesis fiel à natureza, como 
também a imitação dos autores antigos, garantiram um valor artístico suficiente. Por isso, pode-se compreender a imitação dos antigos também como volta à natureza. No início do século XVIII, entendem-se ambos sob o título de mimesis: tanto o reflexo fiel da natureza, nos seus vários sentidos, quanto à imitação dos modelos antigos sob o controle de regras poéticas. A visão de Platão de que o poeta não fazia outra coisa nas suas poesias senão copiar a cópia de uma cópia e, assim, algo imperfeito, pois esse seria infinitamente distante e diferente da verdade, encontra cada vez menos repercussão, até o conceito do possível de Aristóteles se estabiliza como referência dominante. Entende-se agora a mimesis como produção do provável, tentando alcançar uma "presentificação" de algo não presente sob as condições de sua probabilidade. Entretanto, não se deve desconsiderar que também a criação de realidades prováveis, de mundos possíveis, mantém-se comprometida com uma estrutura de mundo compreendida ontologicamente. Essa participação da arte na existência do mundo fundamenta sua beleza. Pois a imitação de um mundo repleto de leis divinas e, por isso, em princípio, bonito, leva também à arte a beleza. Isso vale, paralelamente, para as duplicatas prováveis do mundo, cujas leis de construção correspondem ao mundo experimentado.

Pode-se constatar que os antigos autores e pensadores, apesar de obras artísticas maravilhosas surgindo ao seu redor,

não eram capazes e nem pretendiam separar a qualidade estética dessas obras dos seus contextos morais, religiosos, práticos ou de seus conteúdos. Nem usavam essa qualidade estética como medida para analisar as belas-artes como uma unidade própria ou torná-las objeto de uma interpretação filosófica extensa (CHRISTELLER, 1976, p. 172).

O surgimento de um novo tipo de diferenciação social põe fim não somente à antiga ordem social da Europa, mas também transforma os conceitos referentes ao gosto, arte e poesia contidos nela. No decorrer da diferenciação funcional, os sistemas sociais se especializam em solucionar problemas específicos e se delimitam um ao outro. Política, direito, economia, ciência, arte e religião são diferenciados claramente um do outro, o que resulta em novas leis também no reino do belo. Entendemos a reestruturação da sociedade como uma mudança que cria condições para um sistema de arte e literatura que pode observar e codificar seu ambiente exclusivamente através de critérios estabelecidos por ele próprio. Nesse processo, a literatura se desfaz das suas restrições e vem ter a possibilidade de tratar também o mal, o injusto, o terrível ou o repugnante, sem precisar justificar essas temáticas moral, filosófica ou didaticamente. Vemos essa descentralização 
dentro de uma análise histórica mais abrangente. A sociedade europeia estratificada, formada por classes que determinaram, de forma limitadora, as possibilidades de participação social, cede, a partir do século XV/XVI, gradualmente, a uma reestruturação em direção a sistemas funcionais nos quais o indivíduo pode e deve participar. Isso não quer dizer que camadas sociais mais ou menos favorecidas tenham sido eliminadas, mas a origem familiar e social como base de identidade é substituída pelo conceito de formação (Bildung): a integração social ocorre através da carreira individual, que, por sua vez, resulta da participação em organizações funcionais como escola, universidade ou empresa. A camada social de origem pode ser desfavorável ao indivíduo e até mesmo um obstáculo para ele, mas não serve mais como forma primária de estruturação da sociedade. Em lugar da diferenciação estratificatória de reis, nobres, cleros, cidadãos e agricultores, a sociedade diferenciada funcionalmente organiza-se em áreas como ciência, economia, política, religião, direito, educação, arte etc., na qual cada um desses sistemas exerce uma função específica e exclusiva. A literatura, como parte do sistema da arte, não precisa e nem pode mais se apoiar em normas de ordem moral, religiosa, social ou poética, mas ganha autonomia e experimenta até a exigência de desenvolver reflexões e programáticas próprias que a diferenciem e consolidem como área demarcada, específica e única.

\title{
RESUMO
}

O presente artigo pretende analisar os escritos de Johann Christoph Gottsched, Johann Jakob Bodmer e Johann Jakob Breitinger. Entende-se que suas reflexões marcam o fim do período histórico da sociedade estratificada com suas poéticas reguladoras e normativas. Apesar de sua inserção no pensamento antigo, encontram-se nos textos dos referidos autores certos traços e reflexões iniciais sobre a diferenciação da literatura em direção a um campo próprio que objetiva se distanciar das delimitações sociais e estéticas baseadas na mimese e moral.

Palavras-chave: Johann Christoph Gottsched; Johann Jakob Bodmer; Johann Jakob Breitinger.

\begin{abstract}
This article analyses Johann Christoph Gottsched, Johann Jakob Bodmer and Johann Jakob Breitinger's compositions. Their poetic reflections mark the end of a historical period characterized by a stratified social structure and its regulating and
\end{abstract}


normative poetics. Even though their reflections are rooted in traditional concepts, certain traces and initial reflections on the differentiation of modern literature and its forthcoming autonomy that will reject social delimitations and esthetics based on mimesis and morality can be found.

Keywords: Johann Christoph Gottsched; Johann Jakob Bodmer; Johann Jakob Breitinger.

\section{REFERÊNCIAS}

BATTEUX, Charles. Einschränkung der schönen Künste auf einen einzigen Grundsatz. Hildesheim: Georg Olms, 1976.

BODMER, Johann Jakob; BREITINGER, Johann Jakob. Schriften zur Literatur. Stuttgart: Reclam, 1980.

BREITINGER, Johann Jakob. Critische Dichtkunst. In: BODMER, Johann Jakob. BREITINGER, Johann Jakob. Schriften zur Literatur. Stuttgart: Reclam, 1980.

BUCHNER, August. Kurzer Weg-Weiser zur Deutschen Tichtkunst. Leipzig: Zentralantiquariat d. Dt. Demokrat. Rep., 1977.

CHRISTELLER, Paul Otto. Humanismus und Renaissance. München: Hanser, 1976.

DOCKHORN, Klaus. Macht und Wirkung der Rhetorik. Bad Homburg: Gehlen, 1968.

DURZAK, Manfred. Zu Gotthold Ephraim Lessing. Poesie im bürgerlichen Zeitalter. Stuttgart: Reclam, 1984.

FISCHER, Ludwig. Gebundene Rede. Tübingen: Niemeyer, 1968.

GOTTSCHED, Johann Christoph. Schriften zur Literatur. Stuttgart: Reclam, 1982.

GRÜBEL, Rainer. Michail M. Bachtin. Die Ästhetik des Wortes. Frankfurt/M.: Suhrkamp, 1979. HERDER, Johann Gottfried. Werke. Berlin: Hempel, 1982.

KLOPSTOCK, Friedrich Gottlieb. Gedanken über die Natur der Poesie. Frankfurt/M.: Insel Verlag, 1989.

KNODT, Eva. Negative Philosophie und dialogische Kritik. Tübingen: Niemeyer, 1988.

LESSING, Gotthold Ephraim. Gesammelte Werke. Berlin: Aufbau Verlag, 1954. v. 6.

LUHMANN, Niklas. Gesellschaftsstruktur und Semantik. Frankfurt/M.: Suhrkamp, 1980.

. Gesellschaftstruktur und Semantik. Frankfurt/M.: Suhrkamp, 1993. v. 3.

MEYER, Reinhart. Restaurative Innovation. In: BÜRGER, Christa (Org.). Aufklärung und literarische Öffentlichkeit. Frankfurt/M.: Suhrkamp, 1980.

SCHERPE, Klaus. Gattungspoetik im 18. Jahrhundert. Stuttgart: Metzler, 1968.

Submetido em: 27/10/2009

Aceito em: 17/02/2010 